\title{
Features of a Project-Case Technology in Teaching Students Further Mathematics
}

\author{
Tatiana Yu. Gorskaya ${ }^{1 *}$, Inna I. Golovanova ${ }^{2}$, Rina S. Khammatova ${ }^{3}$, Anatolii E. Polichka ${ }^{4}$, \\ Leonid N. Romanchenko ${ }^{5}$ \\ ${ }^{1}$ Kazan State University of Architecture and Engineering, Kazan, RUSSIA \\ ${ }^{2}$ Kazan (Volga Region) Federal University, Kazan, RUSSIA \\ ${ }^{3}$ Sechenov First Moscow State Medical University, Moscow, RUSSIA \\ ${ }^{4}$ Pacific National University, Khabarovsk, RUSSIA \\ ${ }^{5}$ Financial University under the Government of the Russian Federation, Moscow, RUSSIA
}

Received 24 June 2020 - Accepted 8 September 2020

\begin{abstract}
The relevance of the research is due to the fact that the study of further mathematics in an engineering university provides the level of general education and general cultural development of students, and educational background in special disciplines for the subsequent professional tasks solution. At the same time, there are significant difficulties in mastering the "Further Mathematics" course by students. In this regard, this work is aimed at solving the problem of improving the process of teaching further mathematics in an engineering university using a combination of project based learning and case study (project-case technology). It contributes to developing professional competencies of students of architectural and engineering specialties through the use of solving practice-oriented problems, which brings them closer to real future professional activities. The leading methods in the problem study were: entrance subject testing of the training level in mathematical; pedagogical observation during lessons where project based learning and case study were used; questionnaires upon completion of the "Further Mathematics" course, aimed at identifying both the level of mathematical maturity and the level of ability to conduct research activities necessary to solve non-standard professional tasks. Methods of mathematical statistics were used to process the experimental data. The main results of the study consist in highlighting the features of the combination of project based learning and case study when mastering the "Further Mathematics" course by students, future architect engineers. The significance of the obtained results lies in the fact that the proposed organization of the educational process can be implemented in various engineering specialties, considering a selection of specific professional case tasks.
\end{abstract}

Keywords: project based learning, case study method, case tasks, teaching further mathematics, engineering education, construction and architecture education

\section{INTRODUCTION}

\section{Topicality of the Problem}

A lot of emphasis is placed nowadays in Russia on creation of high-tech industrial and construction sectors, which is impossible without well-trained engineering personnel. Therefore, special attention is paid to the development of Russian engineering education. Today, the success of a university graduate is determined by his multidisciplinary knowledge, willingness to make nonstandard decisions and the degree of soft skills development. In engineering universities, an important role in the formation of professional competencies belongs to fundamental general theoretical courses, and, first of all, to the course "Further Mathematics". Through mathematics, it is possible to describe and identify essential connections of real phenomena and processes

(c) $\mathbf{2 0 2 0}$ by the authors; licensee Modestum. This article is an open access article distributed under the terms and conditions of the Creative Commons Attribution License (http://creativecommons.org/licenses/by/4.0/). 


\section{Contribution to the literature}

- The article reveals that organization of the educational process will increase the efficiency of mastering the course of "Further mathematics" if a theoretical material is presented in the aspect of students' future professional activities and illustrated with tasks of applied nature, focusing on geometric tasks.

- The article proposes the usage of project-based learning in solving practical case tasks when teaching students - future architect engineers. This method should be implemented with the help of a mathematical apparatus which includes all sections of the course "Further Mathematics". This solution allows students to focus on practical application of mathematics in their future professional activities while designing and calculating architectural objects.

- The article proposes criteria which allow assessing the level of mastering the course "Further Mathematics" by students according to three components of assessment: cognitive, activity and affective. The developed criteria take into account both individual indicators of students' mathematical knowledge and the level of development of professional and general competencies formed as a result of mastering the course and depending, inter alia, on the project complexity, its scope and contribution of an each project participant.

in production activities. The language of mathematics is versatility, and its mastering ensures high-quality training and effective activity of a specialist (Kolmos \& de Graaff, 2014). Being an academic discipline, "Further Mathematics" has a huge both humanitarian and applied potential, allowing to develop skills of future engineers in applied issues, the ability to build and analyze mathematical models of engineering problems, to develop intuition and reflection in forecasting and decision-making under uncertainty. The role of mathematics is also important in forming the brainwork of future builders, designers, architects, technologists, production foremen. The main tasks that the "Further Mathematics" course solves in an engineering university are the following: ensuring the level of general education and general cultural development of students; providing basic training for the study of special disciplines and subsequent professional activities; development of skills of independent work with mathematical material necessary for continuous self-education (Mukhametshin et al., 2019; Ogot \& Okudan, 2007). The overall solution of the listed tasks will allow forming the mathematical aspect of future specialist's readiness for professional activity. At the same time, certain difficulties arise in mastering the course "Further Mathematics" by students. This is due to the fact that this discipline is usually studied during the first year when the student has a vague notion of the future professional activity and, as a result, cannot determine the value of mathematical knowledge in it. In addition, the content of the course itself is mainly abstract in nature and a student cannot independently see its application in practice (Potapova et al., 2018). Therefore, students' interest in mastering further mathematics is rather low, which is manifested in the level of their motivation.

Teaching mathematics in modern universities to this day, basically, remains in the classical traditions of the existing Soviet mathematical school. Traditional teaching technologies, such as lectures, problem solving and theorem proving exercises, developing logic chains of reasoning are most often used by teachers of mathematics. But in modern conditions, with changing educational goals, the traditional approach to organizing training does not provide the expected result. The competence-based approach is taken as a basis for modern educational standards creation, and it implies the goal of training in developing personal ability to navigate in a variety of complex and unpredictable work situations; new educational technologies become a tool to achieve this goal. At present, project based learning and case study, which are so successfully applied abroad, as well as actively used in the educational process in Russian schools, are beginning to be applied in educational programs of higher education. As known, project and research activity is an effective means of forming and developing competencies, because the process of project tasks solution is personality-oriented and is based on various types of activities: educational, reproductive, productive. With this approach, a teacher acts as a consultant, a partner; he does not lead the student in learning, but accompanies him (Orekhovskaya et al., 2019). Thus, it provides an opportunity to independently acquire knowledge and enables formation of students' competencies.

\section{LITERATURE REVIEW}

At present, in order to increase the efficiency of mastering mathematics, practical researchers are considering various possibilities of using active learning technologies in mathematics education. Mixed technology is one of the topical and popular ones, preferred by educators all over the world. The use of digital technologies for online learning and the solution of problem-based professional situations in a classroom (Barham, 2020; Konnova et al., 2019; Naji al., 2019; Raslan et al., 2020; Ratnasari \& Safarini TLS, 2020; Siagian et al., 2019; Ulandari et al., 2019; Yang et al., 2019), the use of a web quest in teaching mathematics (Sanina et al., 2019), 
which is one of the most modern interactive educational technologies, provides high results in mastering mathematics.

The use of project based learning in teaching mathematics (Telegina et al., 2019) helps to increase the level of motivation to study the most difficult topics of the course. Project and research technology, as a system of integrated procedures in the educational process, includes many well-known methods and means of active learning: project based learning, immersive learning, methods of data collection and processing, research and problem-based methods, analysis of reference and literary sources, searching experiment, development work, generalization of results, business and roleplaying games (Bayanova \& Minyaev, 2019; Verbitsky \& Borisova, 1990) and other methods (Kirikova, 2000). The original form of the project and research technology is the project based learning, which is successfully used by teachers in the modern learning process and has been considered both from the standpoint of designing the technology itself (Anoshkin, 1997) and from the standpoint of its application (Baykova et al., 2000).

Based on the experience of implementing project activities (Guzeev, 1998) and the use of project and research technologies in higher professional education from the perspective of a contextual approach (Verbitsky, 1991), it has been established that project activities should be organized in such a way that during its implementation students should acquire the knowledge they need to improve their activities and achieve goals, as well as set the goal to develop their own means of activity. As a result of work on a project, future engineers also develop personal qualities which can be assessed in the dynamics of their development using a ranking score (Gronlund, 1982) and creative abilities (Dietrich, 1981). Thus, in the process of project and research activities, students develop both professional competencies, due to the active acquisition of educational material and obtaining professional skills, and universal competencies (Lebedeva \& Ivanova 2002), necessary for active participation in professional fields of activity. Also, the implementation of project-based tasks provides formation of professional competencies of students, based on understanding and application of interdisciplinary connections (Vilensky, Obraztsov \& Uman, 2005). One of the most effective methods used in projects is the case study method. When solving cases, various forms of student interaction are used with the help of techniques and means for discussing and presenting the results obtained. Various aspects of the case method application in the educational process are reflected in works of both Russian and foreign authors. More recently, the case method has been associated primarily with economic education and business sciences. But lately, more and more people are talking about its application in professional training in general, including humanitarian and technical education. At the present stage of higher education development, there are considered the following aspects of the case study usage: effectiveness of its application in formation of professional competencies by students of economic specialties (Kiyomova, 2017; Zabelina \& Fortunato, 2019) and by students of engineering specialties (Logacheva \& Golovanova, 2019); formation of methodological support (Smolyaninova, 2000) for didactic assistance of educational processes at the university (Golovanova, Asafova, \& Telegina, 2014; Gordeeva et al., 2018). Considering the possibilities of using the case method in studying technical disciplines (Yadav, Shaver, \& Meckl, 2010), we can say that this method is aimed not only at the formation of professional competencies, but also enhances the development of soft skills which characterize the intellectual and communicative levels of students' development (Pokushalova, 2011). Highlighting the strengths of this method and defining case study as an "advanced" active teaching method, attention is paid to its potential in preparation of a math teacher (Dalinger, 2015), indicating the possibility of creating new activity models with the principles of problem-based learning. While teaching mathematics at a technical university, the case method is mostly used in the study of separate matters to increase the efficiency of their development (Salnikova, 2016). In this instance there is a challenge to form not only knowledge of individual elements of mathematics, but also an integral system of mathematical representation (Testov, 2018; Veraksa, Bukhalenkova, \& Kovyazina, 2018).

The analysis of the state of the problem showed a high interest of a pedagogical community in inclusion of the project-based learning method and the case study method in educational practices of higher education, and also revealed a small number of methodological practices in teaching Further mathematics using these methods.

\section{METHODOLOGY}

\section{Purpose of the Study}

The purpose of our study is to identify features of project-based learning combined with a case-method when mastering the "Further Mathematics" course by students - future architect engineers.

Teaching mathematics in technical universities differs in its content, depending both on a training program and on a basic level of training. On the one hand, the discipline, according to requirements of the educational standard, should train the appropriate competencies, on the other hand, pre-university mathematical training of students is not homogeneous and requires teaching of the discipline to align mathematical knowledge in order to maximize student involvement in the learning process. Such tasks are solved in different ways: work with students' 
motivation, focus on their personality traits, inclusion of active methods in teaching. It should be noted that in educational programs of a technical university, the content of "Further Mathematics" is the same for all areas of training. At the University of Architecture and Engineering, teachers of mathematics experience a particular difficulty when teaching students of the architectural department, who demonstrate by a high level of creativity. For mastering the course, according to the academic load, 72 hours $/ 2$ credit points are assigned, including 36 hours of classroom lessons - 18 lectures and 18 practical studies. The learning process is carried out according to a classical "lecture-practice" scheme, where the volume of theoretical material is quite large, and there is not enough time for classroom work. A large proportion is allocated to students' independent work. The existing situation did not suit either students or teachers, since students did not see the subject value, they did not have sufficient basic preparation for independent study, and teachers could not motivate them to master the material.

In this regard, it was proposed to model the educational process of mastering the discipline "Further Mathematics" for architecture students using project based learning so that students could apply the knowledge, gained in mathematics, in practice of their professional activities while designing and calculating architectural objects. We proposed a case study method, which was used to help students create projects and designs of structures and objects through mathematical description of their surfaces.

\section{Research Methods and Techniques}

Organization of the experiment began with the study of theoretical aspects of a project method and case study and their usage in teaching. To carry out project activities by students, a project task was formulated taking into account the content of the "Further Mathematics" course. Then, didactic material was developed, including case tasks. The training program of the course was adjusted, considering the requirements for competencies development determined by the educational program. To collect information, the following research methods were chosen: entrance subject testing of the training level in mathematical; pedagogical observation during lessons where project based learning and case study were used; questionnaires upon completion of the "Further Mathematics" course aimed at obtaining an educational result. Methods of mathematical statistics were used to process the experimental data.

The generated test package made it possible to evaluate both the input level of knowledge, with the help of 15 test tasks, and the level of the ability to conduct research activities necessary for solving non-standard professional tasks. The diagnostic questionnaire contained 100 questions. Comprehensive observation cards were developed, allowing to fix emotional and activity components of the educational process during classroom lessons. A scale for assessing a project and a questionnaire for students' self-assessment at the end of the course "Further Mathematics" were developed.

\section{Research Facilities}

The pedagogical experiment was carried out in the study groups of students from the architectural department of Kazan State University of Architecture and Engineering, with psychological and pedagogical support of the Department of the Higher Education Pedagogy (Institute of Psychology and Education, Kazan Federal University). We selected an experimental group, although the experiment included all students in the same year (170 people), but due to the large amount of data to be further processed, there were randomly selected one study group of 30 people, named 7AP02, and one control group, named 7AP05.

\section{Experiment Stages}

The study was carried out in the period from September 1, 2017 to June 6, 2019 and included in three stages.

At the first stage (September 1, 2017 - September 1, 2018), theoretical preparation of the study was carried out, i.e. acquaintance with the existing state of the research problem, available information, based on the study of scientific articles; the methodology of the scientific research was determined, a program and methods of experimental work were chosen and developed, preparation of necessary diagnostic tools was carried out. The content, composition and degree of development of students' competencies were revealed.

At the second stage (September 1, 2018 - March 1, 2019), a pedagogical experiment was carried out with the use of a project-case technology while studying "Further Mathematics" course by students - future architects. At the same time, the course study program was being adjusted.

At the third stage (March 1, 2019 - June 6, 2019), the processing and interpretation of the research experimental data was carried out.

\section{Application of the Methodology}

Within the framework of the study program for the "Further Mathematics" course, architecture students are expected to study such sections as linear algebra, vector algebra and analytical geometry, differential and integral calculus of functions of one and several variables. According to the curriculum, 8 lectures and 7 practical classes are allocated for the study of this subject; end-of-term test is given in a form of a credit. Considering the small amount of lessons and the 
Table 1. Typical tasks for midterm assessment

\begin{tabular}{|c|c|}
\hline $\begin{array}{l}\text { Controlled results of mastering a competence (or a part } \\
\text { of it) }\end{array}$ & $\begin{array}{l}\text { Formulation of a typical control task or other material necessary to } \\
\text { assess knowledge, skills, abilities and (or) experience }\end{array}$ \\
\hline \multicolumn{2}{|c|}{$\begin{array}{l}\text { Competence to be developed GC-9: Ability to use the basic laws of natural sciences in professional activities and apply } \\
\text { methods of analysis, modeling, theoretical and experimental research }\end{array}$} \\
\hline $\begin{array}{l}\text { Know: Fundamentals of further mathematics, including } \\
\text { algebra, geometry, mathematical analysis. }\end{array}$ & $\begin{array}{l}\text { 1. Distance between points in space. } \\
\text { 2. Definite integral, its application in calculating the area of a plane } \\
\text { figure. }\end{array}$ \\
\hline & 2). \\
\hline $\begin{array}{l}\text { rminology and basic concepts of the } \\
\text { tics course; } \\
\text { kills and basic methods of solving } \\
\text { tical problems used in subjects connect }\end{array}$ & 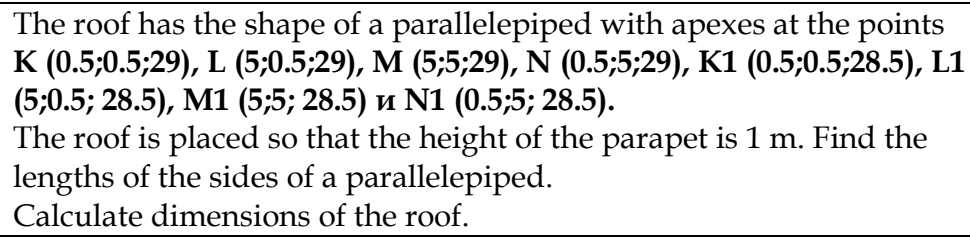 \\
\hline
\end{tabular}

specifics of student groups mastering this discipline, i.e. creative orientation of architecture students, it was proposed to organize training based on project learning and case study. Such educational approach and implementation a competency-based approach to learning arouse practical interest of studying the discipline, considering "Further Mathematics" as a tool for solving problems related to their future professional activities. At the same time, it was necessary to take into account the possibility of realizing cohesion of the subject matter, ensuring the integration of its individual components in one project solution. The result of mastering the discipline "Further Mathematics" by students is the competence development associated with the use of the basics of algebra, geometry, mathematical analysis, discrete mathematics, graphs, combinatory analyses, theory of probability, foundations of statistics and the ability to apply mathematical methods in the development of architectural and urban planning designs. Thus, student groups were offered a case when each student could take part in the work on design an architectural object - a component of researchers' campus. As it is necessary to use a 3D printer to create surfaces of structures, students need to mathematically describe all surfaces of a structure. In addition, the data on the cost of material and construction work, available in the table to the case task, allows them to calculate the cost of the proposed project. The final product (project result) is a presentation of the case solution.

According to the case task, it is necessary to design the town so that it has a presentable appearance, is distinguished by novelty of structures and ease of installation. It is also necessary to calculate the cost of structure erection, and describe the external surfaces of each building using mathematical formulas. The project result should be in the form of a presentation.

Implementation of projects on solving problems of a professional orientation also acted as a means of midterm assessment for evaluation of educational results defined in the course study program and announced to students at the first lecture (Table 1).

The experimental activities were carried out as follows.

At the first lecture, students were given an educational task to perform a project work related to the mathematical description of external surfaces of architectural objects developed by students. This task was presented in the form of a case, which main idea was to combine individual solutions of students into a single project. The main task of the case was to create a concept for a residential complex by the entire student group, for example, a camp for researchers. The case task was presented in the following description:

"A research expedition is being organized. To ensure its work, it is necessary to build a camp in the shortest possible time. In the expedition area, nearly the Kuibyshev reservoir, close to Kadyshevo village (Russia, Tatarstan), there are some building materials and human resources. A 3D printer capable of creating objects from concrete or glass is also available. However, it creates the surface only if it is mathematically defined. The team, which includes architects, communication engineers, must build the camp on time and at a certain cost.

Architects need to design an expedition camp. The costs of conducting communications should not be taken into account, we consider them secondary.

Production conditions and cost of work:

1. Since the printer is given by sponsors, the cost of its maintenance and management is not included in the cost of work; only consumables are taken into account. In one shift, it prints $5 \mathrm{~m}^{3}$ of concrete or 3 tons of silica sand.

2. A team of workers is hired with a payment of 10,000 rubles per shift. For a shift, they carry out work on the development and installation of $10 \mathrm{~m}^{3}$ of the material, erection of structural steel is done about 1 ton per shift. 
Table 2. The cost of materials and services

\begin{tabular}{lccc}
\hline No & Item & Unit of measure & Cost (rub) \\
\hline 1 & Board lumber & Cubic meters & 6700 \\
2 & Concrete & Cubic meters & 3000 \\
3 & Double-glazed windows 4 mm & Square meters & 560 \\
4 & Stainless metal 2 mm & $\mathrm{kg}$ & 140 \\
5 & Silica sand & ton & 1300 \\
\hline
\end{tabular}

3. The cost of other consumables (glue, fasteners, connecting elements) can be neglected and considered insignificant.

4. The cost of work on other materials development, which are not included in Table 2, can be found independently, orienting towards prices of the region.

5. The table shows the cost of materials and services.

\section{Purpose:}

Design the town so that it has a presentable appearance, is distinguished by novelty of structures and ease of installation.

Tasks:

1. Describe the external surfaces of each building using mathematical formulas.

2. The project result should be in the form of a presentation.

To work on the project on developing a concept of the structure, which surfaces can be graphs of known functions, students teamed up in groups of three. Study of theoretical material, necessary for implementation of the project, was reviewed in a classroom (lecture and practical lessons). At each lecture, theoretical material was accompanied by applicable illustrations, related to the upcoming project work of students.

To get acquainted with the main theoretical aspects necessary to solve the case, seven lectures were held.

At the first lecture, students were offered a "Coordinate method for solving geometric problems", which incorporated the basic concepts of linear and vector algebra. Also, as examples of theoretical material application, practical problems related to construction and calculation of the main elements of linear structures were used.

The second lecture included an introduction to second order curves, space curves, helix, second order surfaces, and surfaces of revolution. An example of describing a structure surface in the form of surface matching was also considered.

The third lecture was devoted to the basic elementary functions of one variable and their graphs. We also considered surfaces formed by rotating the graph of a function of one variable. The description of architectural structure elements was carried out using graphs of elementary functions.

In the fourth lecture, the functions of two variables and their graphs were studied. The description of an architectural structure was shown through graphs of functions of two variables.

In the fifth lecture, the differential calculus of functions of one and two variables was considered. The lecture was purely theoretical and introduced the material necessary for the next educational questions.

The sixth lecture dealt with the integral calculus of a function of one variable and its application to solving geometric problems. Examples of calculating the areas of plane figures, the lengths of arc curves, including spatial curves, the volumes of revolution bodies were reviewed. As an example, we considered:

1) calculation the area of a flattened structure portion with an analytical description,

2) length of the spiral arc, which is the basis of a spiral staircase in a structure,

3) calculation of the material volume required to fill the conical structure with the given size, and walls of the cone determined by a mathematical description.

At the final lecture there were considered integral calculus of a function of two variables, calculation of the volumes of spatial bodies, surface integral, and also the surface area of a structure was calculated.

In practical classes, students tried to solve test questions and analyze particular solutions similar to those that projects may contain. In total, seven practical classes were held.

Practical class 1: use of a coordinate method for geometric problems. Calculation of the beam length and angles between the beams. Areas of parallelograms and volumes of tetrahedrons.

Practical class 2: graphs of functions on a plane, surfaces of revolution.

Practical class 3: functions of two variables and their graphs.

Practical class 4: definite integrals, calculating the areas of plane figures.

Practical class 5: use of a definite integral to calculate the length of an arc curve, volumes of revolution bodies.

Practical class 6: double integral, calculation of body volumes.

Practical class 7: surface integral. Calculation of surface area.

During the practical classes, groups carrying out their project could contact a teacher with any questions they might have. During the classroom work, the teacher was 
monitoring the progress of preparation and implementation of projects. The main criteria for the analysis of students' activities were: understanding the purpose of a project; involvement in activities, effective use of educational material received in a classroom, distribution of roles in the group and organization of communication processes. The teacher recorded the observation results in a special map.

At the final lessons, students were surveyed about the degree of project readiness; the teacher explained conditions for presentation of projects. At the end of the course, the conference "Mathematics in Architecture" was organized with presentations of student projects.

The final assessment for the project consisted of assessment of work on a project, which was carried out by a teacher during training, and the results of a project presentation, which was carried out by an expert group consisting of teachers of the Department of Further Mathematics. Assessment of work on the project included three components: cognitive, activity and affective. The cognitive component of the project assessment included complexity of work, ability to independently acquire necessary knowledge, correctness of work in terms of mastering the mathematical apparatus; contribution of each group member was taken into account and evaluated. The activity component of the assessment was based on student's activity in each lesson, ability to set a research goal, ability to correct work considering new knowledge, desire to perform a high quality project, contribution of each participant was assessed. The affective component of the assessment included the degree of involvement of each project participant in a research. This analysis was carried out by the teacher through observation during the entire course. The presentation of a project was assessed according to the criteria: complexity, quality of project implementation, quality of computer presentation, ability to present work (public speaking). Based on the results of the project activities, a reflexive analysis was carried out with the students in the form of answers to the questions: what they liked, what they learned, how the student showed himself by completing the task. Self-assessment, largely, is the work of identifying one's strengths and weaknesses, which is necessary first of all for the person himself. Selfassessment is not a criterion for evaluating a project, it only helps a student to logically complete the work.

There is an example of project implementation within a case.

The architectural structure created as part of a project is a set of the following mathematical forms: prism, parallelepiped, cone, cylinder, surfaces of sine and tangent curves.

The prism is set by the following points:

A $(0 ; 0 ; 0)$, B $(6 ; 0 ; 0), C(6 ; 6 ; 0), D(0 ; 6 ; 0), A 1(0 ; 0 ; 30), B 1$ $(6 ; 0 ; 30)$, C1 $(6 ; 6 ; 30)$ и D1 $(0 ; 6 ; 30)$.

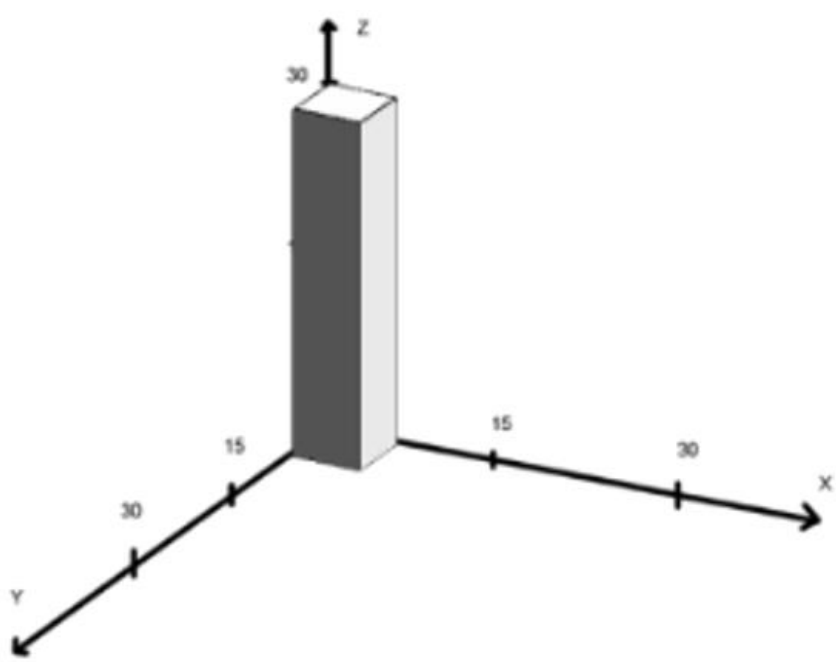

Figure 1. Parallelepiped in a three-dimensional coordinate system

We have a parallelepiped with side lengths of 6,6 and 30 meters.

Vwalls $=6 * 6 * 30-5 * 5 * 30=1080-750=330\left(\mathrm{~m}^{3}\right)$

Since half of the tower will have glass walls, we calculate the area of the tower walls:

$\mathrm{S}=6^{*} 30 * 4=720\left(\mathrm{~m}^{2}\right)$

Tower roof:

The roof has the shape of a parallelepiped (Figure 1) with apexes at the points $\mathrm{K}(0.5 ; 0.5 ; 29), \mathrm{L}(5 ; 0.5 ; 29)$, $\mathrm{M}$ $(5 ; 5 ; 29)$, N (0.5;5;29), K1 (0.5;0.5;28.5), L1 (5;0.5; 28.5), M1 $(5 ; 5 ; 28.5)$ и $\mathrm{N} 1(0.5 ; 5 ; 28.5)$.

The lengths of the parallelepiped sides are 5.5 and 0.5 meters. The roof is placed so that the height of the parapet is $1 \mathrm{~m}$.

The volume of the roof:

$\mathrm{V}=5 * 5 * 0.5=12.5\left(\mathrm{~m}^{3}\right)$

Truncated cone (Figure 2):

Outer wall boundary:

$$
\left\{\begin{array}{c}
\frac{(x-15)^{2}}{15^{2}}+(y-15)^{2}-(z-15)^{2}=0 \\
0 \leq z \leq 6
\end{array}\right.
$$

Inner wall boundary:

$$
\begin{gathered}
\left\{\begin{array}{c}
\frac{(x-15)^{2}}{15^{2}}+\frac{(y-15)^{2}}{0.5^{2}}-(z-15)^{2}=0 \\
0 \leq z \leq 6
\end{array}\right. \\
V_{\text {cone }}=\frac{1}{3} \pi R^{2} h \\
V_{1}=\frac{1}{3} \pi * 15^{2} * 15-\frac{1}{3} \pi * 9^{2} * 9=\frac{1}{3} \pi(3375-729) \\
=882 \pi \approx 2769.48\left(\mathrm{~m}^{3}\right) \\
V_{2}=\frac{1}{3} \pi * 14,5^{2} * 15-\frac{1}{3} \pi * 8,5^{2} * 9 \\
=\frac{1}{3} \pi(3153.75-650.25)=834.5 \pi \approx \\
\approx 2620.33\left(\mathrm{~m}^{3}\right) \\
V_{\text {walls }}=V_{1}-V_{2}=2769.48-2620.33=149.15\left(\mathrm{~m}^{3}\right)
\end{gathered}
$$




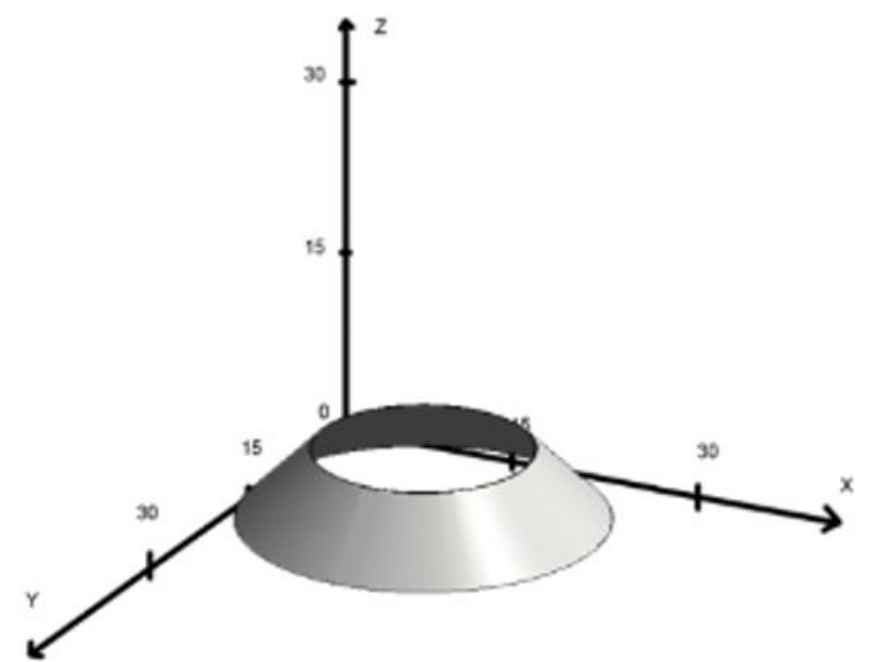

Figure 2. Truncated cone in a three-dimensional coordinate system

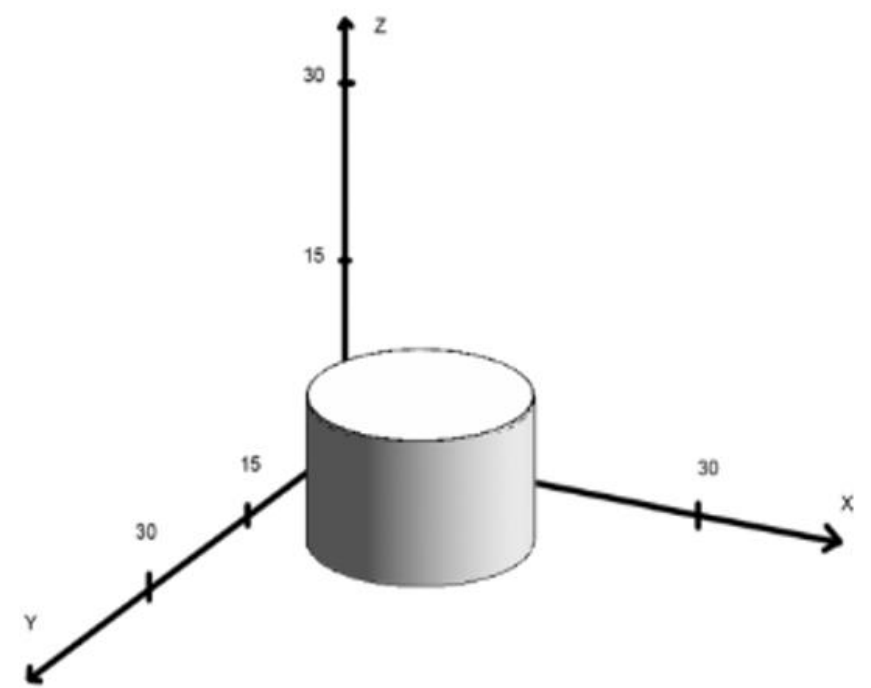

Figure 3. Cylinder in a three-dimensional coordinate system

Cylinder (Figure 3):

Equation of cylinder

$$
\left\{\begin{array}{c}
(x-15)^{2}+(y-15)^{2}=81 \\
0 \leq z \leq 12
\end{array}\right.
$$

Wall surface area:

$$
S=2 \pi R h=2 * 9 * 12 * \pi=216 \pi \approx 678.24\left(\mathrm{~m}^{2}\right)
$$

Cylinder roof: $1 \mathrm{~m}$.

The roof is placed so that the height of the parapet is

Let us define a plane, parallel to the plane $(\mathrm{O} ; \mathrm{x} ; \mathrm{y})$, raised to a height of $12 \mathrm{~m}$ along the $\mathrm{z}$ axis, with the point A $(6 ; 15 ; 12)$ and the vector $\bar{n}(0 ; 0 ; 1)$.

The roof plane equation becomes:

$$
\left\{\begin{array}{c}
(x-15)^{2}+(y-15)^{2} \leq 81 \\
z=12
\end{array}\right.
$$

The volume of the roof, taking into account that its thickness is $0.5 \mathrm{~m}$ :

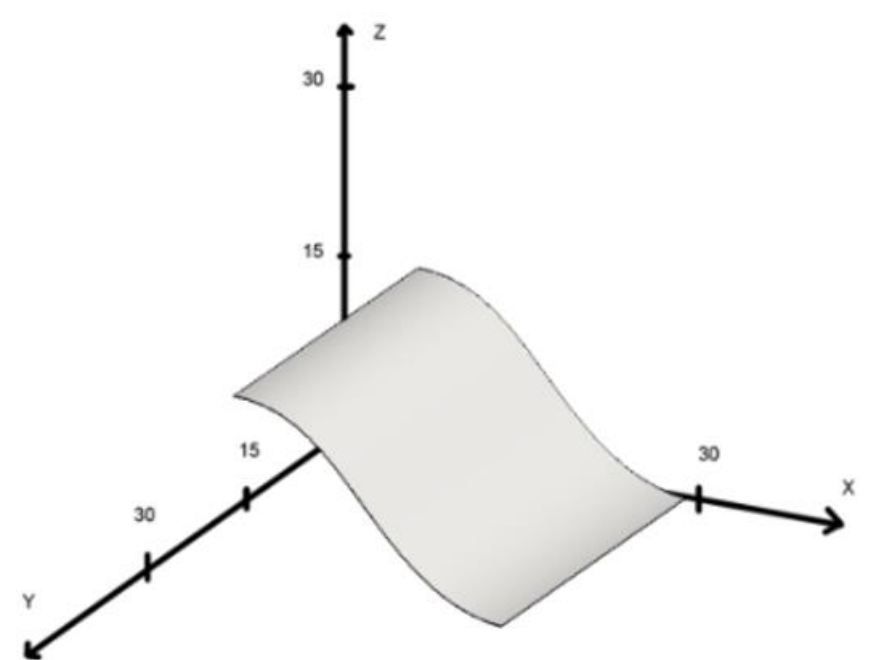

Figure 4. Surface of a sinusoid in a three-dimensional coordinate system

$$
V_{\text {roof }}=81 * 0,5 \pi=40,5 \pi \approx 127.17\left(\mathrm{~m}^{3}\right)
$$

The curved roof has a sinusoidal shape (Figure 4$)$, which is described by the formula:

$$
\left\{\begin{array}{c}
y=\sin x \\
x \in[6 ; 30] \\
y \in[0 ; 30] \\
z=15 \cos \left(\frac{\pi(x-6)}{48}\right)
\end{array}\right.
$$

Let us find the length of the arc:

$L_{1}=\int_{6}^{30} \sqrt{1+\cos x} d x=21.178(\mathrm{~m})$

The volume of the roof, taking into account that its thickness is $0.5 \mathrm{~m}$ and its length is $30 \mathrm{~m}$.

$\mathrm{V}=21.178 * 0.5 * 30=317.67\left(\mathrm{~m}^{3}\right)$

A wall in the form of a tangent curve (Figure 5) is given by the formula:

The coefficient $\mathrm{k}$ :

$$
\left\{\begin{array}{c}
0 \leq x \leq 6 \\
0 \leq z \leq 30 \\
0 \leq y \leq 30 \\
z=\operatorname{tg} \frac{\pi k}{12}
\end{array}\right.
$$

$$
\begin{gathered}
\left\{\begin{array}{c}
-\frac{\pi}{2} \leq k x \leq \frac{\pi}{2} \\
0 \leq x \leq 6
\end{array}\right. \\
\left\{\begin{array}{c}
-\frac{\pi}{2 k} \leq x \leq \frac{\pi}{2 k} \\
0 \leq x \leq 6
\end{array}\right. \\
0 \leq x \leq \frac{\pi}{12}
\end{gathered}
$$

The length of the arc:

$$
L=\int_{0}^{6} \sqrt{1-\frac{1}{\cos ^{2} x} d x}=26(\mathrm{~m})
$$

The volume of the wall, if its thickness is $0.5 \mathrm{~m}$, and its length is $12 \mathrm{~m}$. 


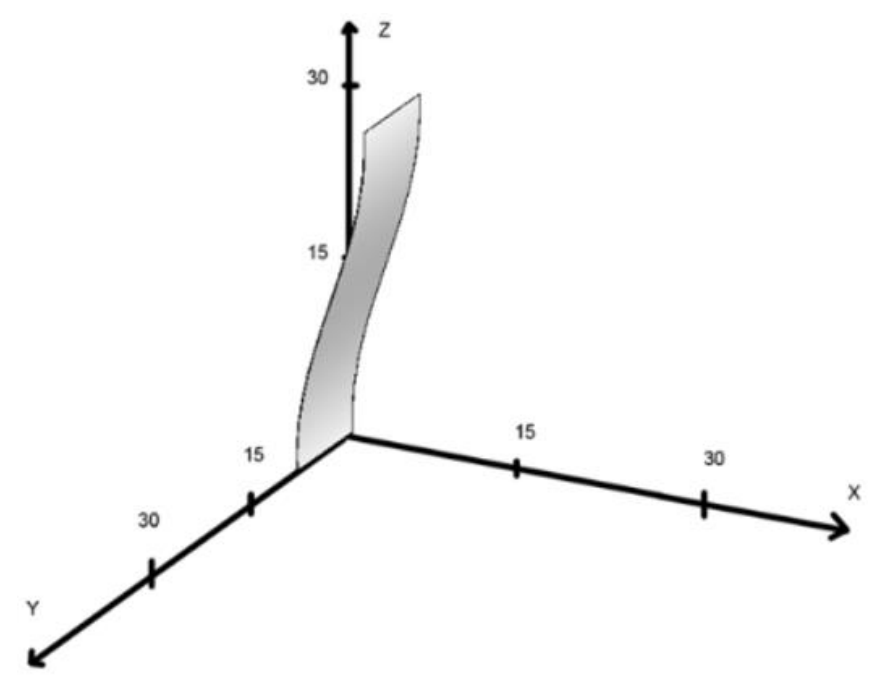

Figure 5. Surface of tangent curve in a threedimensional coordinate system

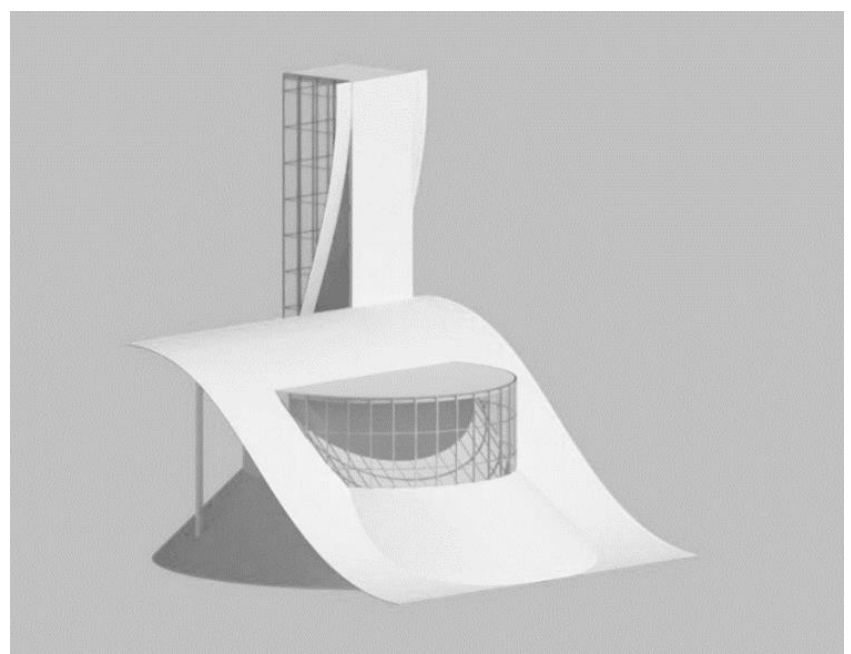

Figure 6. General view of the structure

$$
\mathrm{V}=26 * 0,5 * 12=156\left(\mathrm{~m}^{3}\right)
$$

Cost calculation:

We mean 8 columns, the volume of each is $3.75 \mathrm{~m}^{3}$ (parallelepipeds with sides of 0.5, 0.5 and $15 \mathrm{~m}$ ).

Concrete: cone + sinusoid + tangent curve + cylinder roof $+1 / 2$ tower + tower roof: $=3000(149.15+317.67+$ $156+127.17+330 / 2+12.5)=3000 * 927.49=2782470$ (rub.)

Glass: cylinder $+1 / 2$ tower $=560(678.24+720 / 2)=560$ * $1038.24=581414.4$ (rub.)

Wood: columns $=6700 * 3.75 * 8=201,000$ (rub.)

Workers: $149.15+317.67+156+127.17+165+12.5$ $+30=957.49(\mathrm{~m} 3)$

$957.49 / 10=95.749=96$ (shifts) - required for installation

$96 * 10000=960,000$ (rub.)

Total construction costs (Figure 6):

$2782470+581414+201000+960000=4524884(\mathrm{rub}$.

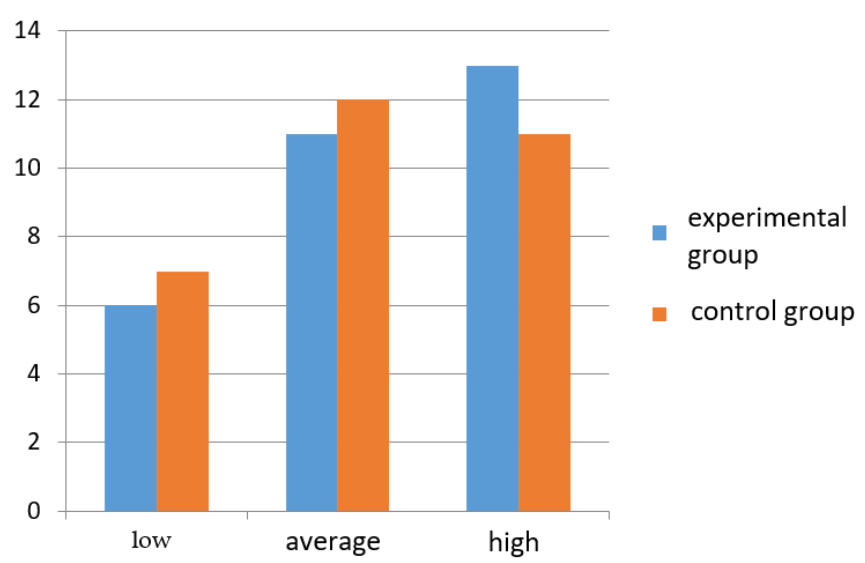

Figure 7. Entrance testing results in mathematics

\section{RESULTS AND DISCUSSIONS}

Entrance testing in mathematics in the control group showed that 7 people have a low level of knowledge, 12 people have an average level, 11 people have a high level; in the experimental group: 6 people have a low level of knowledge, 11 people have an average level, 13 people have a high level (Figure 7). At the initial stage, according to the $\chi^{2}$ criterion, these two groups are similar in terms of result values.

Evaluation of the effectiveness of educational activities for mastering the course "Further Mathematics" in the experimental group was carried out by evaluating project activities and included criteria for three components of the assessment: cognitive, activity and affective. In a group of 30 students, 10 projects were prepared. The scores obtained were transferred to a ratio scale showing the following data: 1 project received a low rate of assessment, 4 projects - an average rate, 5 projects - a high rate (Figure $8 \mathrm{~b}$ ).

In the control group, the learning outcomes for mastering the course "Further Mathematics" were obtained during the final testing, which was carried out in the traditional form and assessed the personal results of each student (Figure 8a).

As can be seen from the pie charts, the value results of the experimental group are higher, however, the form of assessment in the experimental and control groups was different and in order to compare these results it is necessary to use the Chi-square test, the empirical value of which is calculated by the following formula:

$$
\chi^{2}=N M \sum_{i=0}^{n} \frac{\left(\frac{n_{i}}{N}-\frac{m_{i}}{M}\right)^{2}}{n_{i}+m_{i}},
$$

with $n_{i}$ - a number of elements of one group that received the $i^{\text {th }}$ point. For another group, $m_{i}-$ is the number of its elements that received the $i^{\text {th }}$ point. For verification, we will use the data table. The value of the criterion $\chi^{2}=0.23$, which is less than the critical one; it means that we can compare the means of the samples. 


\section{Control group. Final test}

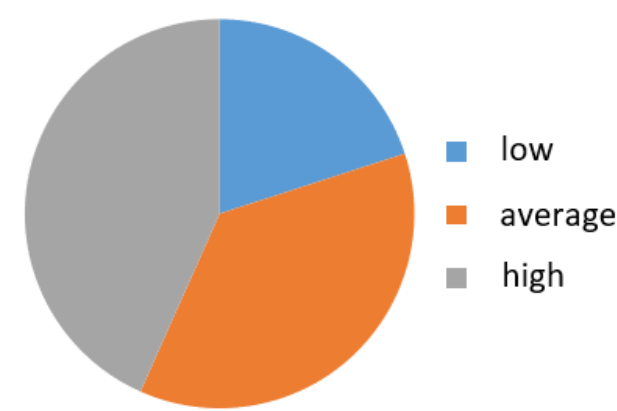

(a) student group 7AP05, 30 people
Experimental group. Assessment of projects

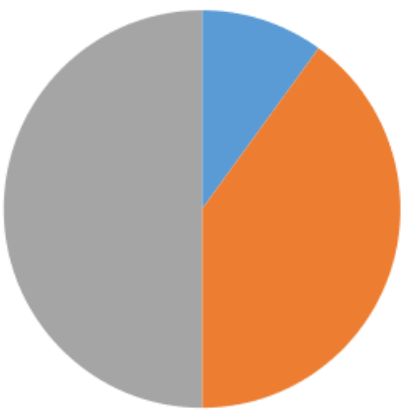

low

average

high

(b) student group 7AP02, 30 people

Figure 8. The effectiveness of training in the course "Further Mathematics": a) control group, b) experimental group

Table 1. Summary data on two measurements of learning outcomes in the experimental group and the final measurement in the control group

\begin{tabular}{lccc}
\hline \multirow{2}{*}{$\begin{array}{l}\text { Scale (point) } \\
\text { Control group at the end of testing }\end{array}$} & $\begin{array}{c}\text { Experimental group } \\
\text { At the beginning of the }\end{array}$ & $\begin{array}{c}\text { At the end of the experiment } \\
\text { (projects) }\end{array}$ \\
\hline Low & $5(16.66 \%)$ & $6(20 \%)$ & $1(10 \%)$ \\
Average & $13(43.34 \%)$ & $11(36.66 \%)$ & $4(40 \%)$ \\
High & $12(40 \%)$ & $13(43.34 \%)$ & $5(50 \%)$ \\
\hline
\end{tabular}

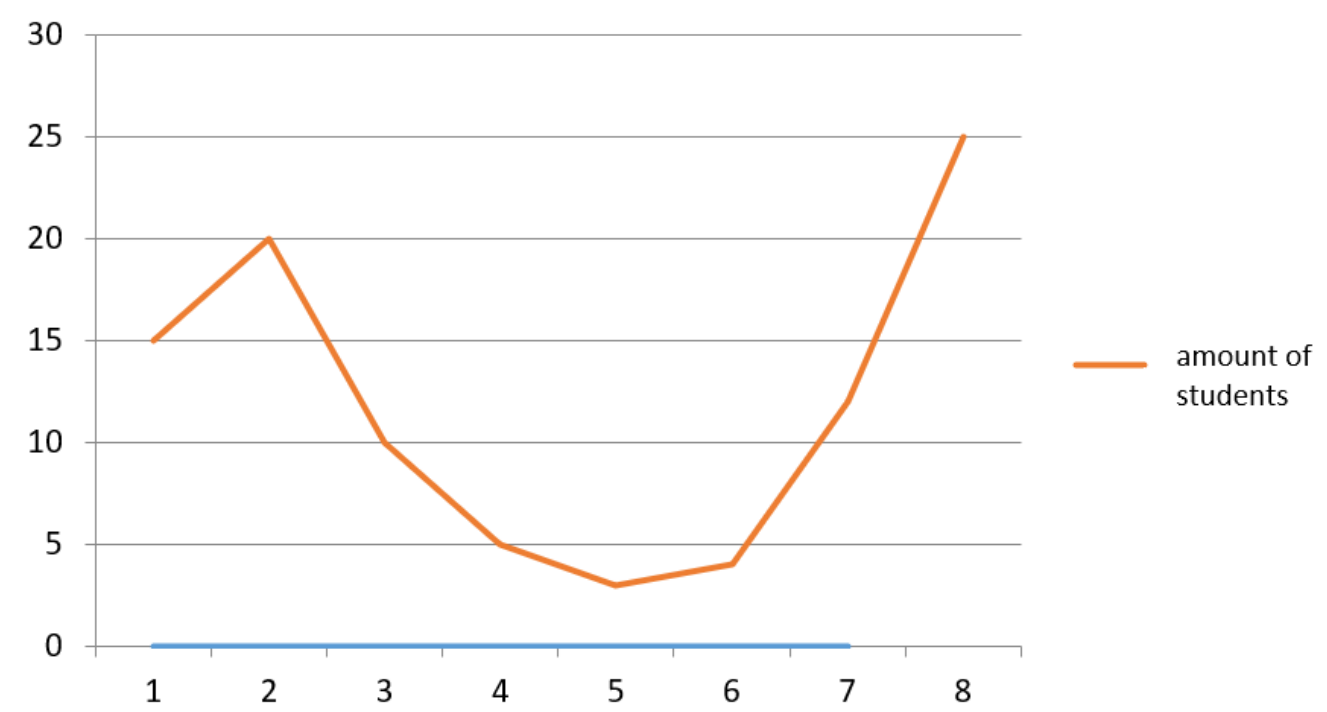

Figure 9. Dynamics of students' requests with questions about the project

In order to compare the results of the initial testing with the final one in the experimental group, but carried out according to different criteria, it is necessary to show the similarity of the two samples, i.e. entrance testing and project assessment data. Will use the criterion $\chi^{2}$. For convenience, we present the data for two samples in Table 1.

The obtained observed value of the criterion $\chi^{2}=1$, which is less than the critical value (5.99), and therefore they can be compared. Table 1 shows that the low level has decreased to $10 \%$, in comparison with the previous $20 \%$. Thus, the number of low performing students has decreased, and the number of students with high level has increased to $50 \%$. Small group work has proven to be beneficial as students with high level of knowledge can help the low performing ones improve and thereby build own potential.

At the same time, the following fact is interesting. The amount of students' questions to the teacher on implementation of the project was measured. Measurements were carried out throughout the entire training course and are presented in the form of a graph (Figure 9). 
The horizontal axis is the time of requests (weeks), the vertical axis is the number of students with requests. In the first week, half of the students were puzzled by implementation of the project, thus, they had ideas and, therefore, questions on project implementation. In the second week, even more students were involved in the project process and they also had specific questions about the work. Closer to the middle of the course, the activity decreased, this can be explained by several reasons: emotional "fatigue", the research task was fully understood and it remained just to be realized. By the end of the course, new questions arose related to the result presentation, difficulties in the project design, and, perhaps, because of a deadline of the project. This is because the emotional attitude is difficult to maintain at a high level.

According to the test results, it was revealed that the percentage of students with a low level of knowledge decreased to $10 \%$ comparing with $23.33 \%$. Thus, the number of weak students has decreased. At the same time, the number of excellent students (showing high level of knowledge) has increased to $50 \%$ in comparison with the previous $36.67 \%$. Low-performing students improved, moving into the category of "Average" in terms of knowledge, and a part of average students moved into the category of students with "High" level of knowledge. Working together on projects in small groups proved to be beneficial as the learning potential of each participant increased on average.

Throughout the experiment, with the exception of a slight emotional standstill at the beginning, there was an active involvement in the process of work on projects by students.

\section{CONCLUSION}

The experimental work has made it possible to improve the quality of students' educational results obtained in mastering the "Further Mathematics" course, as well as to improve the program of the mathematical course at the Kazan State University of Architecture and Engineering.

The use of a project-case technology has been introduced in the process of studying the "Further Mathematics" course by students - future architecture engineers. It is shown that the presentation of theoretical math material in the aspect of students' future professional activity, with an emphasis on geometry and applied tasks, contributes to an increase in educational results.

It is recommended to implement project cases using a mathematical apparatus that includes all sections of the course, thereby integrating separate segmental parts of the discipline into a single complete mathematical worldview.

It is also presented that development of the mathematical apparatus from the standpoint of new geometric forms generated by a variety of mathematical functions, allows you to create new, original architectural solutions.

To assess the quality of the educational process, it is proposed to include the following components into a course study program (in addition to the knowledge component): the level of complexity of a project, its workload, and contribution of each project participant.

The significance of the obtained results lies in the fact that the proposed organization of the educational process can be implemented in various engineering specialties, considering a selection of specific professional case tasks.

\section{ACKNOWLEDGEMENTS}

1. The work is performed according to the Russian Government Program of Competitive Growth of Kazan Federal University.

2. The publication has been supported by the 'Russian Academic Excellence Project 5 - 100' of the I M Sechenov First Moscow State Medical University (Sechenov University).

3. The work is performed according to the Program of Development of Financial University under the Government of the Russian Federation for 2020.

\section{REFERENCES}

Anoshkin, A. P. (1997). Pedagogical design of teaching systems and technologies. Omsk: Omsk State Pedagogical University.

Barham, A. I. (2020). Investigating the Development of Pre-Service Teachers' Problem-Solving Strategies via Problem-Solving Mathematics Classes. European Journal of Educational Research, 9(1), 129. 141. https:/ / doi.org/10.12973/eu-jer.9.1.129

Bayanova, L. F., \& Minyaev, O. G. (2019). Cultural Congruence Test for Russian Adolescents. Psychology in Russia: State of the Art, 12(3), 163-176. https://doi.org/10.11621/pir.2019.0312

Baykova, L. A., Grebenkina, L. K., Eremkina, O. V., Zhokina, N. A., Martishina, N. V., \& Tsirulnikova, O. F. (2000). Pedagogical excellence and pedagogical technology. Moscow: Russian Pedagogical Society.

Blinnikova, I. V., Rabeson, M. D., \& Izmalkova, A. I. (2019). Eye Movements and Word Recognition during Visual Semantic Search: Differences between Expert and Novice Language Learners. Psychology in Russia: State of the Art, 12(1), 129-146. https://doi.org/10.11621/pir.2019.0110

Dalinger, V. A. (2015). Case study in training a math teacher. International Journal of Experiential Education, 3(3), 427-430.

Dietrich, J. (1981). Design and construction: A systematic approach. Moscow: Mir Publ. 
Golovanova, I. I., Asafova, E. V., \& Telegina, N. V. (2014). Interactive learning practices: textbook of methods. Kazan: Kazansky universitet Publ.

Gordeeva, T. O., Sychev, O. A., Pshenichnuk, D. V., \& Sidneva, A. N. (2018). Academic Motivation of Elementary School Children in Two Educational Approaches - Innovative and Traditional. Psychology in Russia: State of the Art, 11(4), 19-36. https:/ / doi.org/10.11621/pir.2018.0402

Gronlund, N. (1982). Design achievement tests. London: Prentice Hall.

Guzeev, V. V. (1998). Development of educational technology. Moscow: Pedagogy.

Kirikova, Z. Z. (2000). Pedagogical Technology: Theoretical Aspects. Yekaterinburg: Publishing House of Ural state professional and pedagogical university.

Kiyomova, K. A. (2017). Case study in practical training as an accelerator of the pedagogical process. Young Scientist, 21, 423-424.

Kolmos, A., \& de Graaff, E. (2014). Problem-based and project-based learning in engineering education. Cambridge handbook of engineering education research, 1, 141-161. https://doi.org/10.1017/CBO97811390 13451.012

Konnova, L., Lipagina, L., Postovalova, G., Rylov, A., \& Stepanyan, I. (2019). Designing adaptive online mathematics course based on individualization learning. Education Sciences, 9(3), 182-196. https://doi.org/10.3390/educsci9030182

Lebedeva, L. I. \& Ivanova, E. V. (2002). Project based learning in effective training. School Technologies, 5, 116-120.

Logacheva, A. G., \& Golovanova, I. I. (2019). Effectiveness of a case study method in formation of professional competencies of undergraduates of a technical university. Problems of modern teacher education, (63-4), 148-151.

Mukhametshin, R. Z., Kryukova, N. I., Beloborodova, A. V., Grinenko, A. V., \& Popova, O. V. (2019), Implementation of efficient energy policy in Russia: Energy consumption monitoring and problem analysis. International Journal of Energy Economics and Policy, 9(4), 224-232. https:/ / doi.org/10.32479/ ijeep.7967

Naji, K. K., Ebead, U., Al-Ali, A. K., \& Du, X. (2020). Comparing Models of Problem and Project-Based Learning (PBL) Courses and Student Engagement in Civil Engineering in Qatar. Eurasia Journal of Mathematics, Science and Technology Education, 16(8), em1867. https:/ / doi.org/10.29333/ejmste/8291

Ogot, M., \& Okudan, G. E. (2007). Systematic creativity methods in engineering education: a learning styles perspective. International Journal of Engineering Education, 22(3), 566-576.
Orekhovskaya, N. A., Chistyakov, A. A., Kryukova, N. I., Krokhina, J. A., Ospennikov, Y. V., \& Makarova, E. V. (2019). Orthodoxy and modernity their contact facets in Russian society. European Journal of Science and Theology, 15(2), 67-77.

Pokushalova, L. V. (2011). Case study method as a modern technology for professionally oriented student education. Young Scientist, (5-2), 155-157.

Potapova, S. V., Danilova, I. Y., Prasolov, V. I., Makarova, E. V., \& Kryukova, N. I. (2018). Mythological foundations of ontology. XLinguae, 11(2), 672-685. https://doi.org/10.18355/XL.2018. 11.02 .53

Rasslan, S., Arisha Haj Ihia, H., Haj-Yahia, S., \& RasslanSharif, A. (2020). The Discovery Approach Strategy in Solving Hard Mathematics Problems: A Case Study. Contemporary Mathematics and Science Education, 1(1), ep20004. https:/ / doi.org/10.30935/ conmaths / 8449

Ratnasari, R., \& Safarini TLS, D. (2020). Problem-Solving Strategies Used by Eight Grade Students. Contemporary Mathematics and Science Education, 1(2), ep20008. https://doi.org/10.30935/ conmaths / 8497

Salnikova, M. G. (2016). Features of the use of a case study method in teaching mathematics to students of a technical university. Modern educational technologies in the world educational space, 4, 147-152.

Sanina, Y. I., Artyukhina, M. S., Dendeberya, N. G., Savadova, A. A., \& Nasikan, I. V. (2019). The use of internet technologies in teaching bachelorseconomists mathematics as a factor of students' professional growth. International Journal of Recent Technology and Engineering, 8(2), 3877-3880. https:/ / doi.org/10.35940/ijrte.B3078.078219

Siagian, M. V., Saragih, S., \& Sinaga, B. (2019). Development of Learning Materials Oriented on Problem-Based Learning Model to Improve Students' Mathematical Problem Solving Ability and Metacognition Ability. International Electronic Journal of Mathematics Education, 14(2), 331-340. https:/ / doi.org/10.29333/iejme/5717

Smolyaninova, O. G. (2000). Didactic possibilities of the case study method in teaching students. Humanitarian Bulletin, 3, 32-35.

Telegina, N. V., Drovosekov, S. E., Vasbieva, D. G., \& Zakharova, V. L. (2019). The use of project activity in teaching mathematics. Eurasia Journal of Mathematics, Science and Technology Education, 15(8), 1738. https:/ / doi.org/10.29333/ ejmste/108439

Testov, V. A. (2018). Integration of discreteness and continuity in forming mathematical world view among students. Integration of Education, 22(3), 480492. https:// doi.org/10.15507/1991-9468.092.022. 201803.480-492 
Ulandari, L., Amry, Z., \& Saragih, S. (2019). Development of Learning Materials Based on Realistic Mathematics Education Approach to Improve Students' Mathematical Problem Solving Ability and Self-Efficacy. International Electronic Journal of Mathematics Education, 14(2), 375-383. https://doi.org/10.29333/iejme/5721

Veraksa, A. N., Bukhalenkova, D. A., \& Kovyazina, M. S. (2018). Language Proficiency in Preschool Children with Different Levels of Executive Function. Psychology in Russia: State of the Art, 11(4), 115-129. https:/ / doi.org/10.11621/pir.2018.0408

Verbitsky, A. A. (1991). Active Learning in Higher Education: A Contextual Approach. Moscow: Vysshaya shkola Publ.

Verbitsky, A. A., \& Borisova, N. V. (1990). Methodical recommendations for conducting business games. Problems of educational psychology and psychology of education, 4, 73-84.
Vilensky, M. Ya., Obraztsov, P. I., \& Uman, A. (2005). Technologies of professional education in higher education. Moscow: Yurait.

Yadav, A., Shaver, G. M., \& Meckl, P. (2010). Lessons learned: Implementing the case teaching method in a mechanical engineering course. Journal of Engineering Education, 99(1), 55-69. https:/ / doi.org /10.1002/j.2168-9830.2010.tb01042.x

Yang, Y., Zhang, Q., Liu, B., Wang, L., \& Kong, X. (2019). Case design of linear algebra hybrid teaching model under problem-based learning International. Journal of Information and Education Technology, 9(9), 618-622. https://doi.org/10.18178/ijiet.2019.9.9. 1277

Zabelina, E. V., \& Fortunato, V. J. (2019). Development of a Russian Version of the MindTime Profile Inventory: The Measurement of Past, Present, and Future Thinking in a Russian Sample. Psychology in Russia: State of the Art, 12(2), 146-164. https://doi.org/10.11621/pir.2019.0211

\section{http://www.ejmste.com}

